\title{
Passive biaxial tensile dataset of three main rat heart myocar- dia: Left Ventricle, Mid-wall and Right ventricle
}

\author{
Fulufhelo Nemavhola ${ }^{*}$, Harry Ngwangwa ${ }^{1}$ Thomas Franz $^{2,4,5}$, Neil Davies ${ }^{3}$ \\ 1 Unisa Biomechanics Lab, Department of Mechanical and Industrial Engineering, School of Engineering, \\ College of Science Engineering and Technology, University of South Africa, Unisa Science Campus, Johan- \\ nesburg, South Africa; masitfj@unisa.ac.za \\ 2 Division of Biomedical Engineering, Department of Human Biology, University of Cape Town, Observatory \\ 7925, South Africa; thomas.franz@unisa.ac.za \\ 3 Cardiovascular Research Unit, Department of Surgery, University of Cape Town, Observatory 7925, South \\ Africa; neil.davies@unisa.ac.za \\ 4 Centre for High Performance Computing, Rosebank 7700, South Africa; thomas.franz@unisa.ac.za \\ 5 Bioengineering Science Research Group, Engineering Sciences, Faculty of Engineering and the Environment, \\ University of Southampton, Southampton SO171BJ, UK; thomas.franz@unisa.ac.za \\ * Correspondence: masitfi@unisa.ac.za ; Tel.: (+27 (011) 471 2765)
}

\begin{abstract}
This article presents raw data of biaxial tensile measurements of rat heart passive myocardium conducted in lab scale environment. The passive myocardium of the rat was divided into three regions, namely: left ventricle, mid-wall and right ventricle. The biaxial dataset of passive rat myocardia is presented as stress vs strain of the passive rat myocardium in various regions. The determination of valid material properties of the heart plays an important role in the development computational models. These computational models are useful in studying various scenarios and mechanisms of heart diseases. In addition, valid and accurate materials are critical in the development of new therapies. The dataset presented here is useful in the area of soft tissue mechanics including studying the mechanisms of heart diseases such as myocardial infarction. Accordingly, the evaluation of stress and strain in left ventricle, mid-wall and right ventricle was performed.
\end{abstract}

Dataset: DOI: 10.17632/y753k82jt4.2.

Dataset License: license under which the dataset is made available (CC0, CC-BY, CC-BY-SA, CCBY-NC, etc.)

Keywords: Cardiac mechanics; Biaxial testing; Rat heart; Left ventricle mechanics; Mid-wall mechanics; Right ventricle mechanics

\section{Summary}

The dataset presented here is useful in the area of soft tissue mechanics and computational biomechanics for the study of the mechanisms of heart diseases such as myocardial infarction. The dataset presented here is useful to researcher communities who have interest in studying various mechanisms of heart diseases. These researchers work in the following research areas: cardiac mechanics, computational biomechanics, cardiovascular regenerative medicine, etc. The data may be used/re-used by determining the material constants of constitutive model (e.g Fung Model) to develop accurate computational models. Cardiovascular diseases are one of the leading causes of the death in the world and as such there is a need for reliable data in the study of such diseases. Various computational studies in myocardial infarction have assumed that the mechanical behaviour of myocardium is homogenous. This assumption may affect the accuracy of developed computational 
models. The data presented here considers three main heart regions and the associated biaxial data is presented.

\section{Data Description}

The shared data shows the mechanical properties of rat myocardium in various regions. The regions considered here are the left ventricle (LV), mid-wall (MDW) and right ventricle (RV). The biaxial stress-strain tensile data (in both fibre and cross-fibre directions) of rat heart myocardium in the LV, MDW and RV are shown in Figure 1 (A-P), Figure $2(\mathrm{~A}-\mathrm{O})$ and Figure $3(\mathrm{~A}-\mathrm{N})$, respectively. Tables 1,2 and 3 shows the maximum tensile force at $40 \%$ strain for $\mathrm{LV}$, MDW and RV regions.

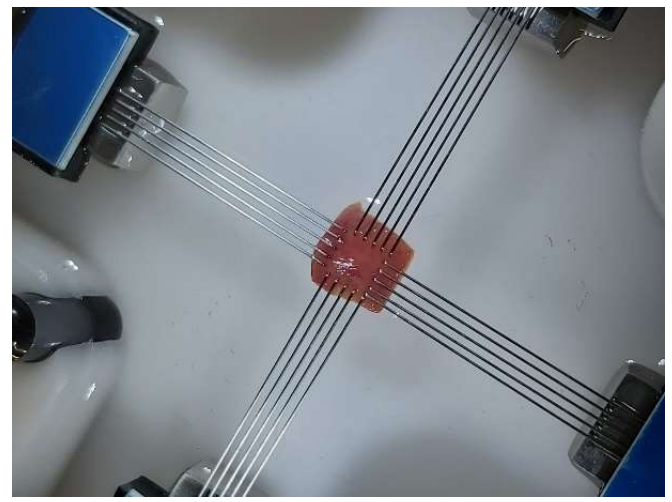

(A)

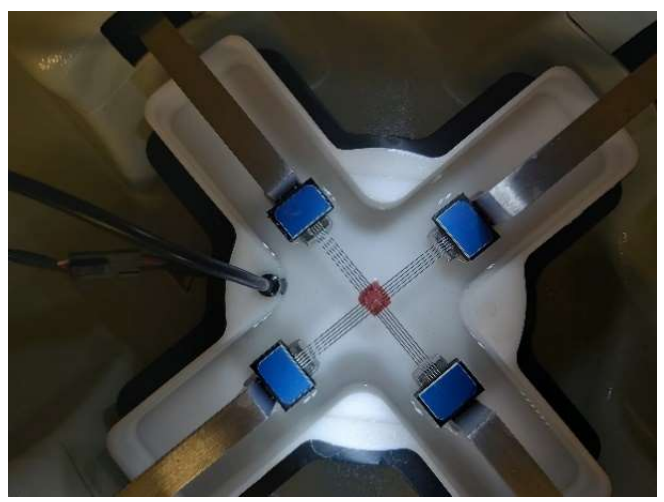

(B)

Figure 1. Experimental set-up of biaxial testing of rat heart passive myocardium. Figure 1 (A) shows the $5 \times 5$ mm LV myocardium sample and rake assembly for clamping. Figure 1 (B) shows the BioTester system used for biaxial testing of rat LV myocardium including the water bath for mimicking the body temperature of $37^{\circ} \mathrm{C}$.

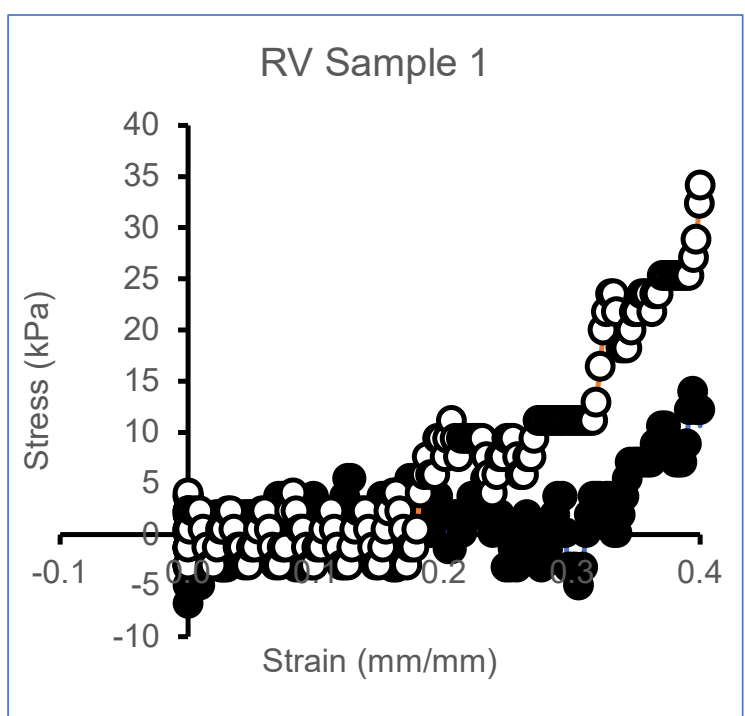

(A)

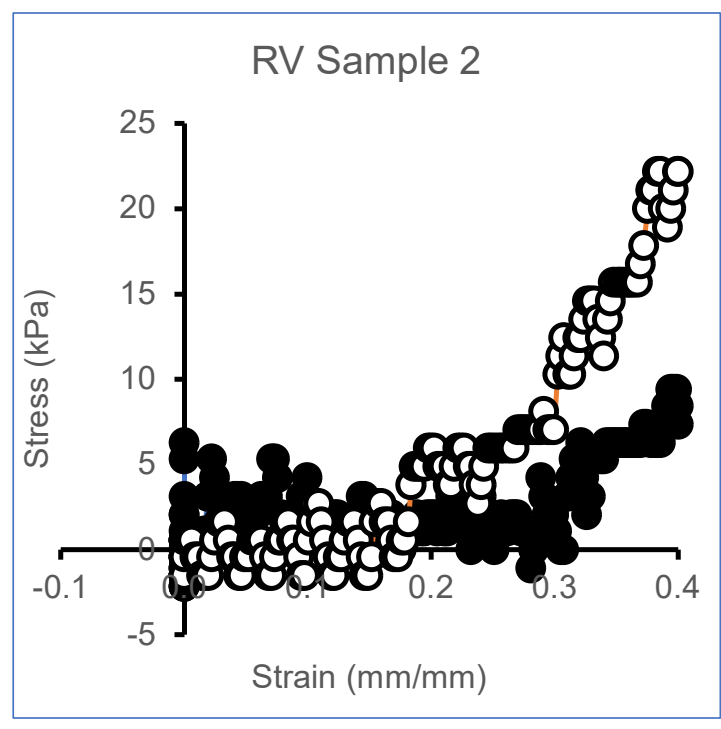

(B) 


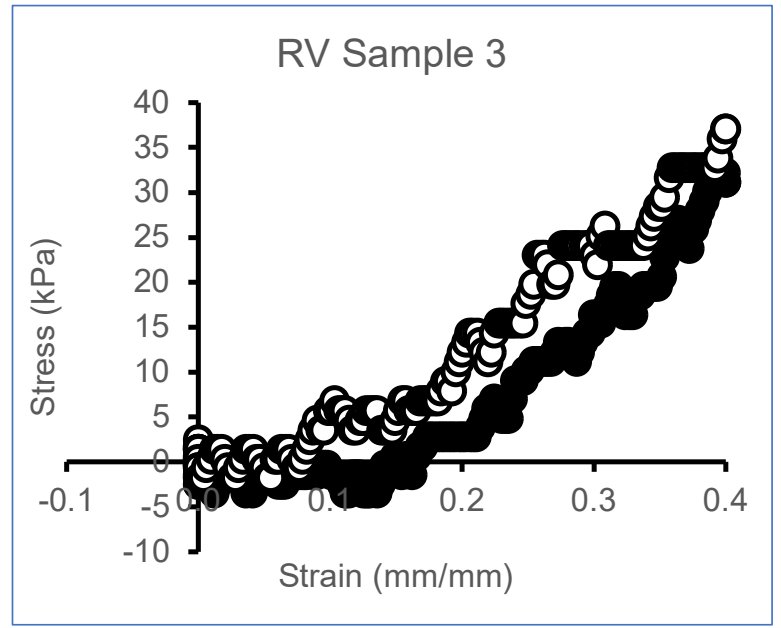

(C)

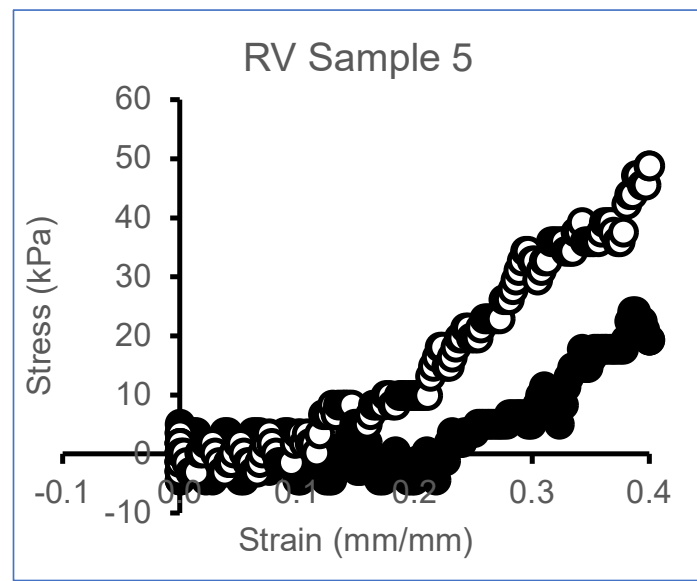

(E)

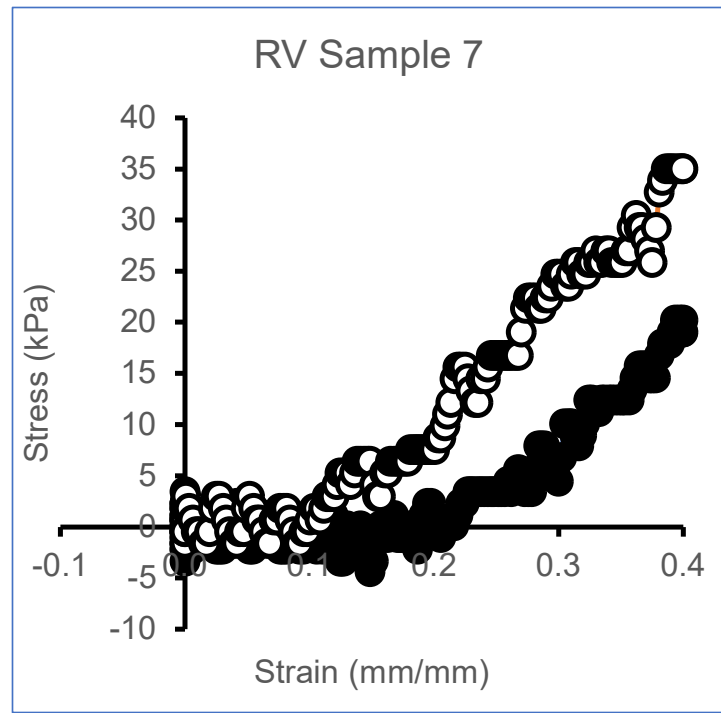

(G)

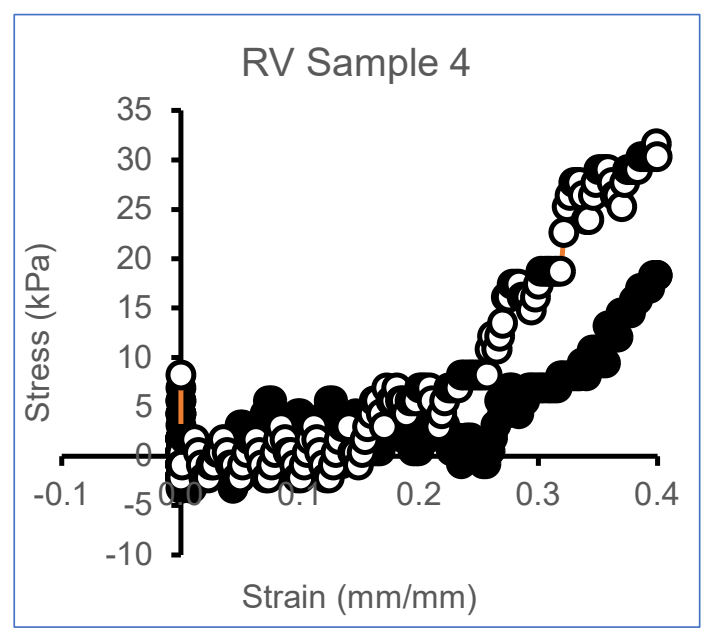

(D)

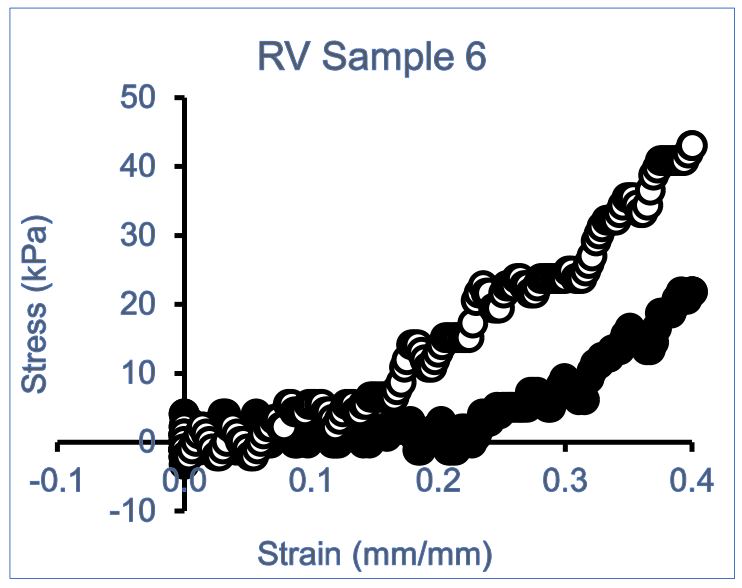

(F)

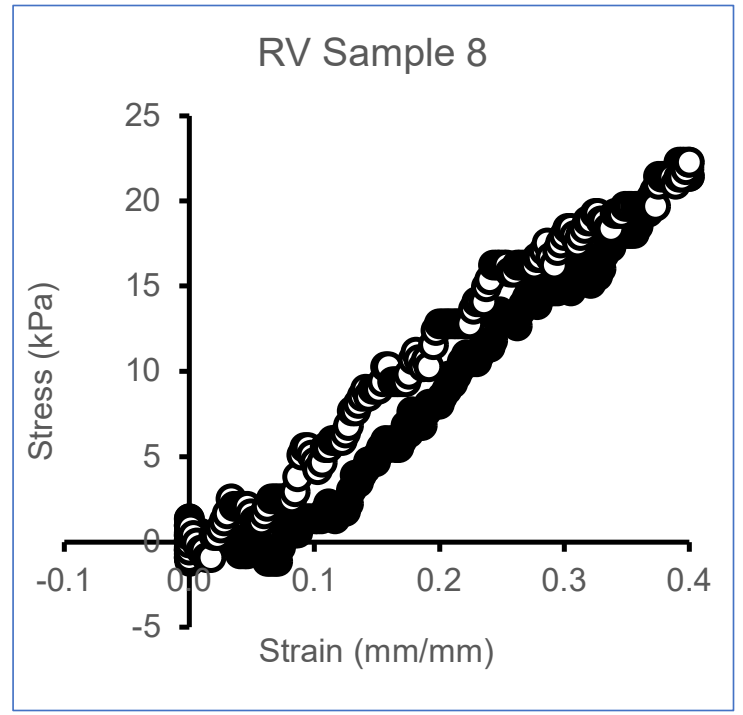

(H) 


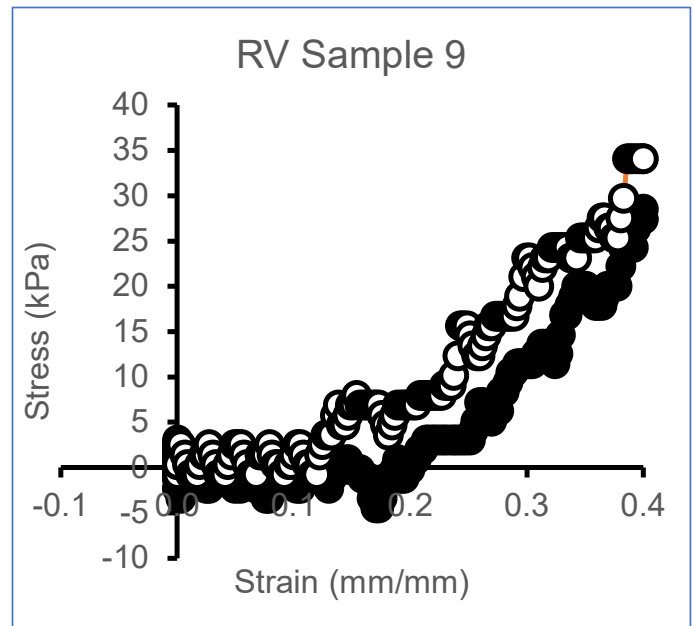

(I)

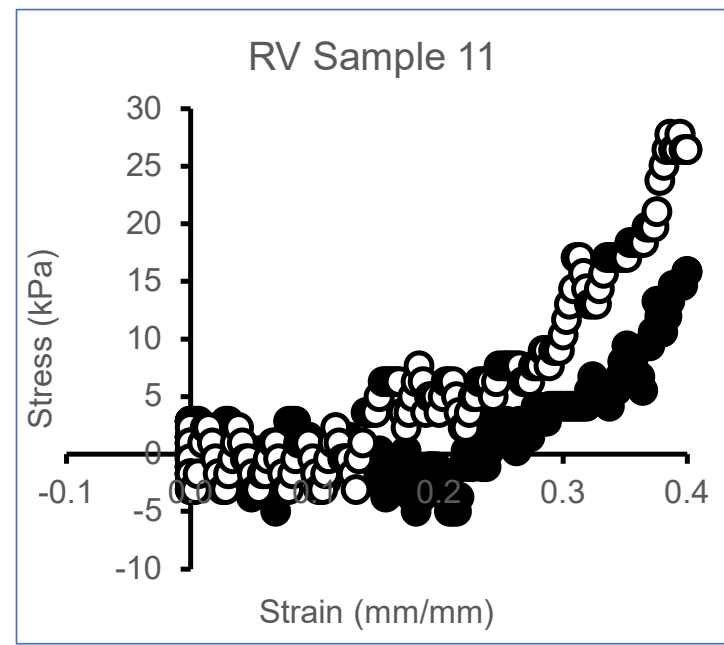

(K)

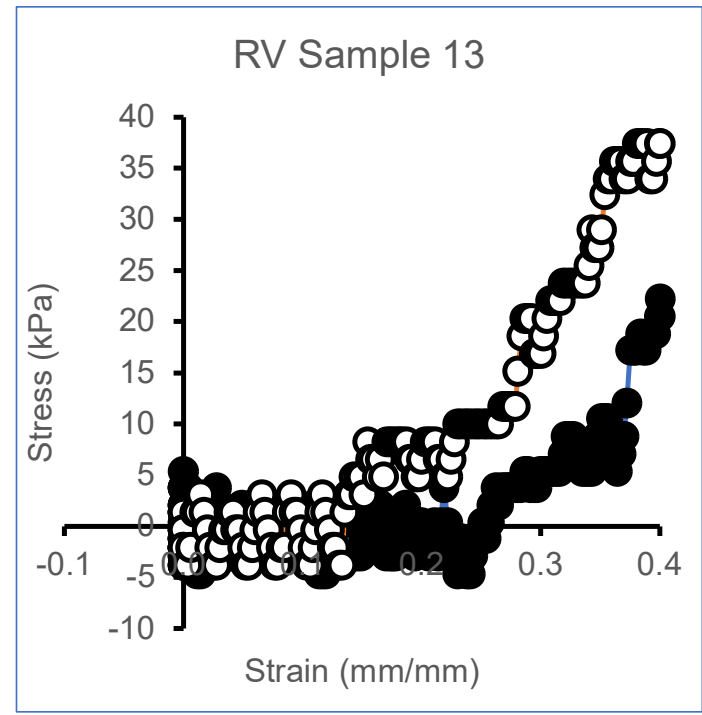

(M)

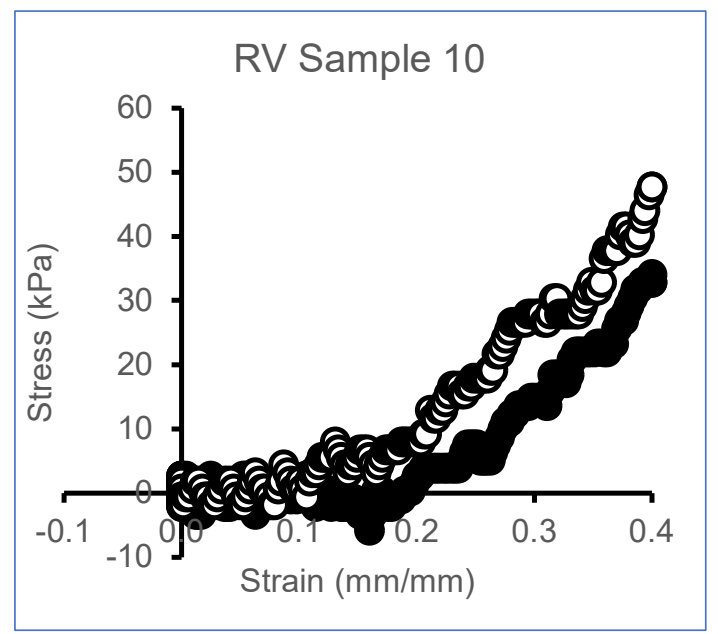

(J)

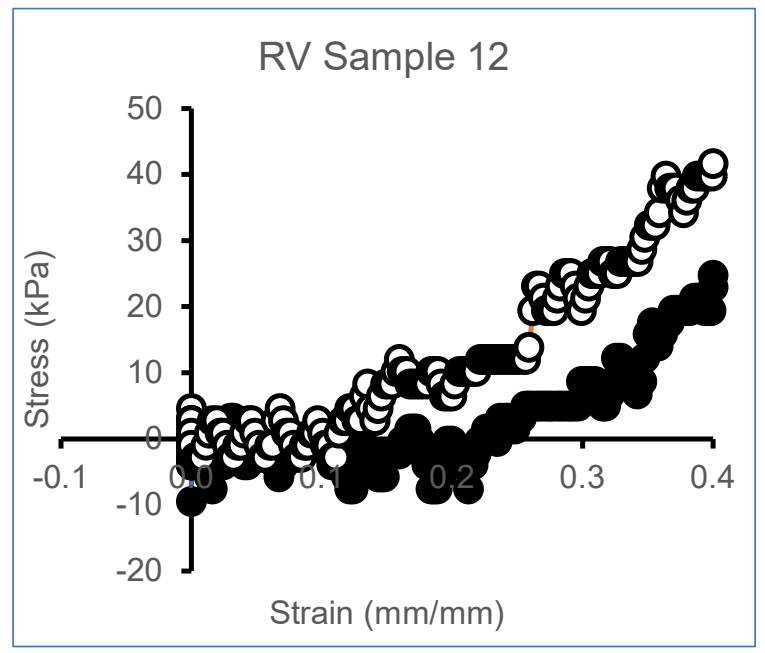

(L)

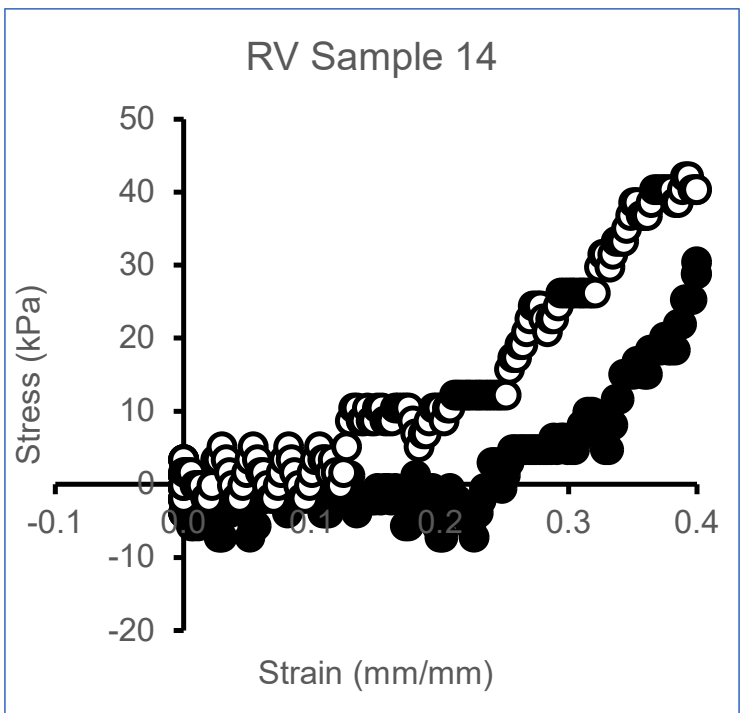

(P)

Figure 2. Stress vs strain plots of RV subjected to biaxial testing showing stress in the fibre and cross-fibre directions. 


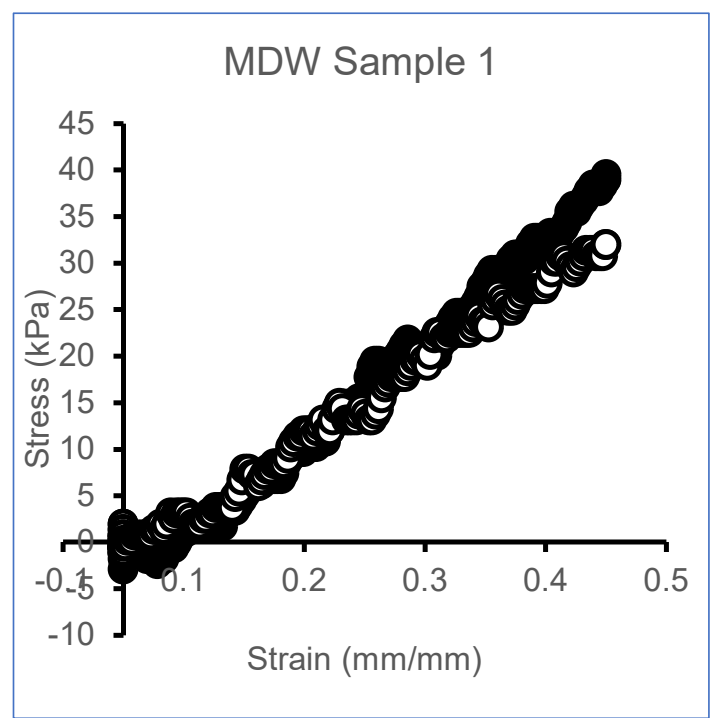

(A)

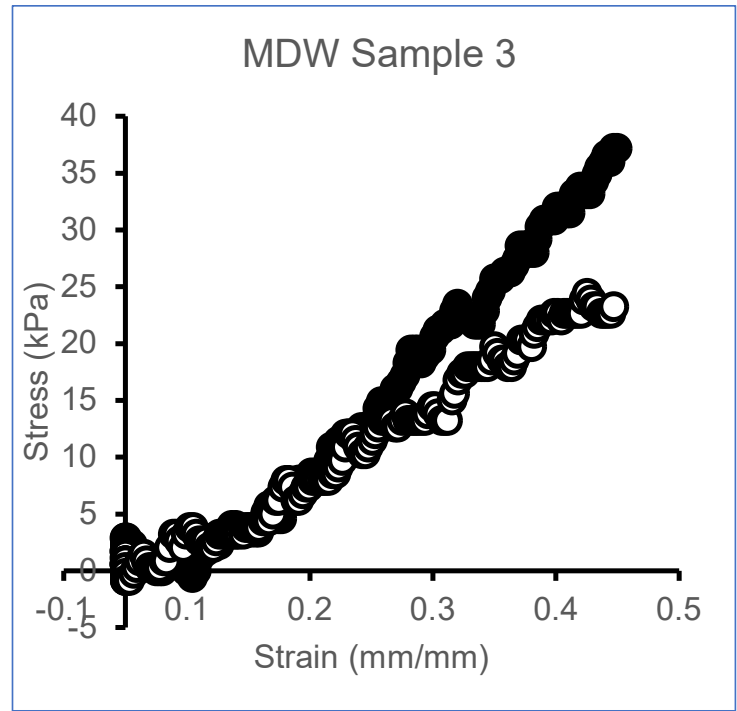

(C)

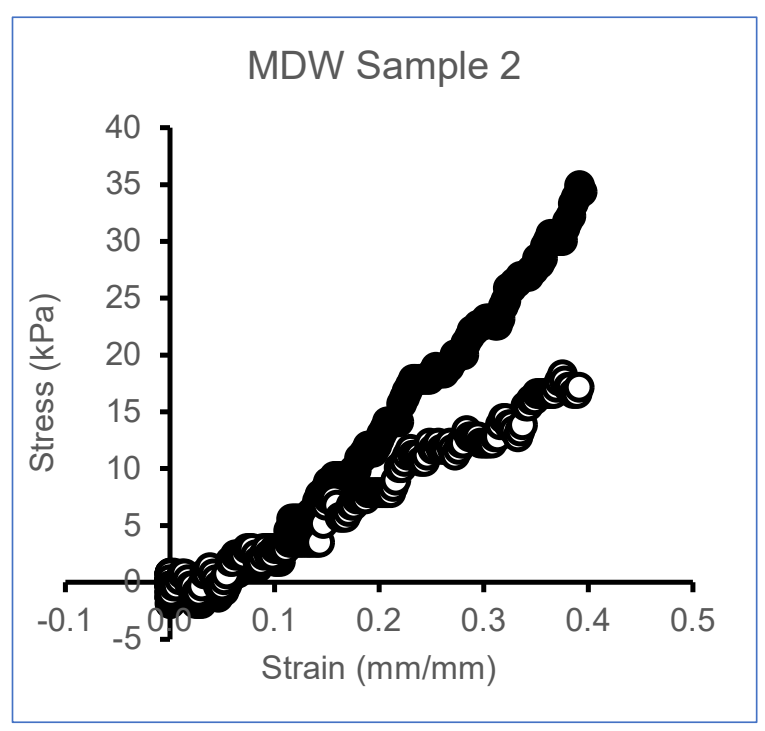

(B)

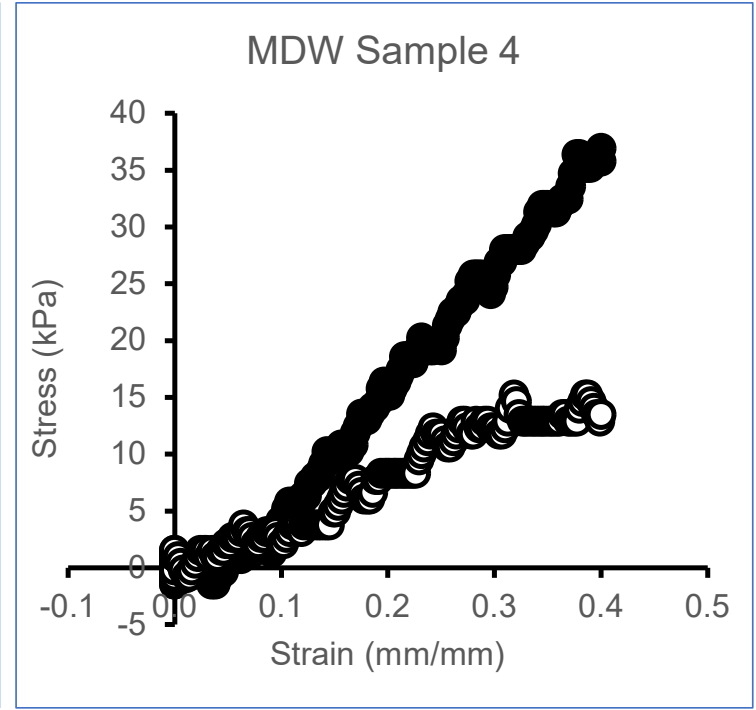

(D) 


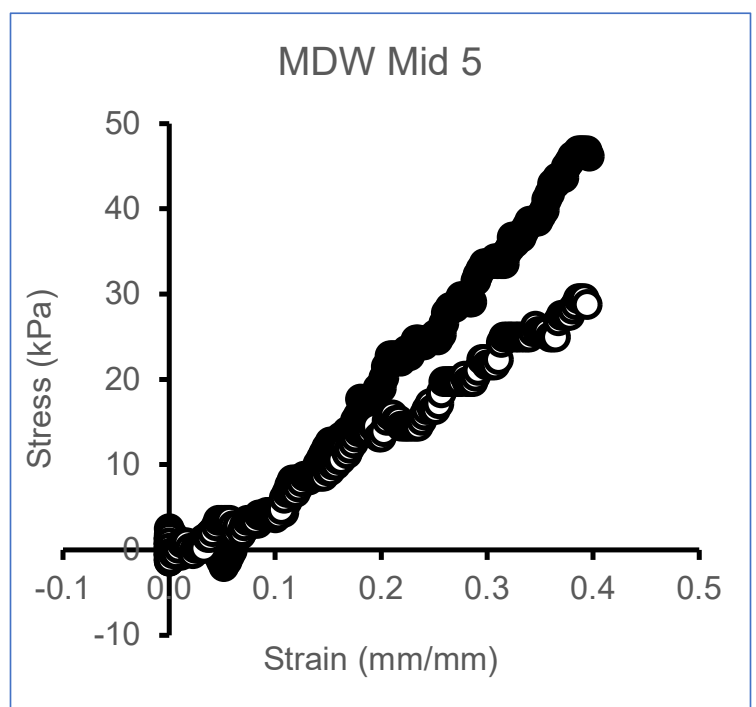

(E)

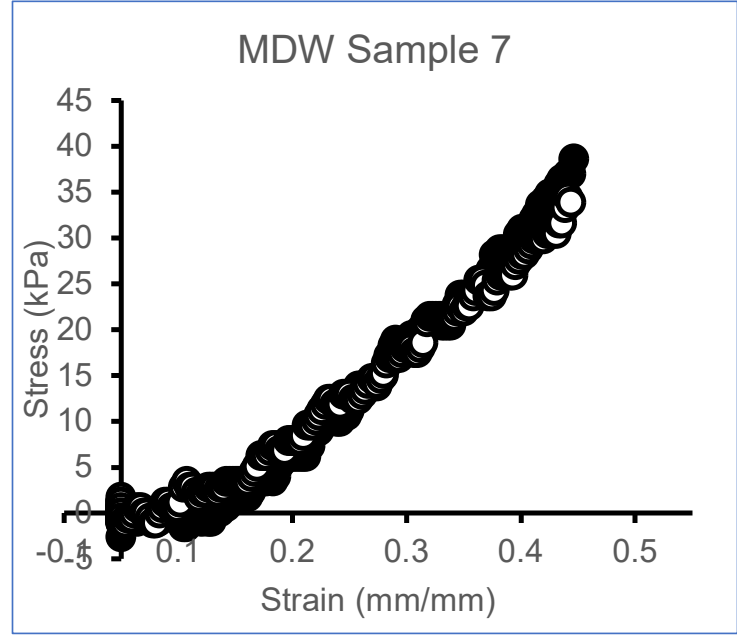

(G)

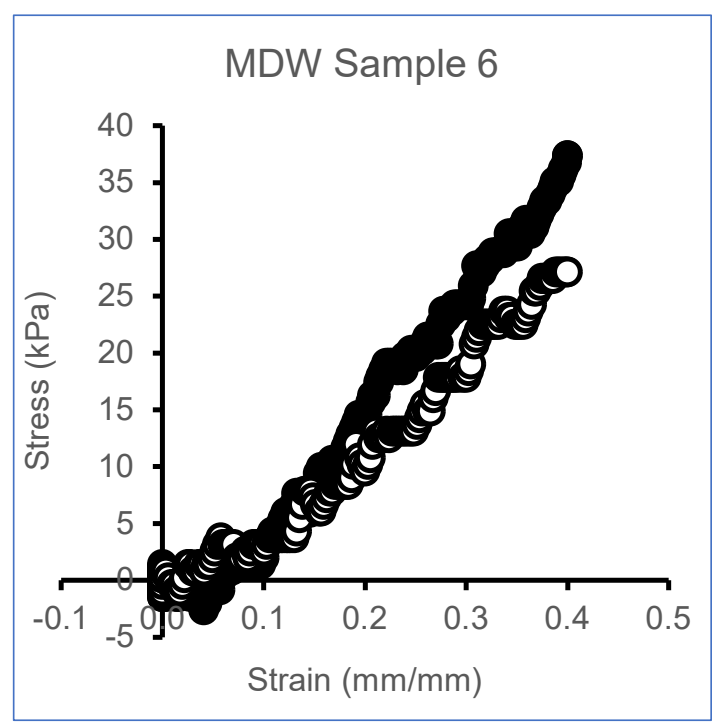

(F)

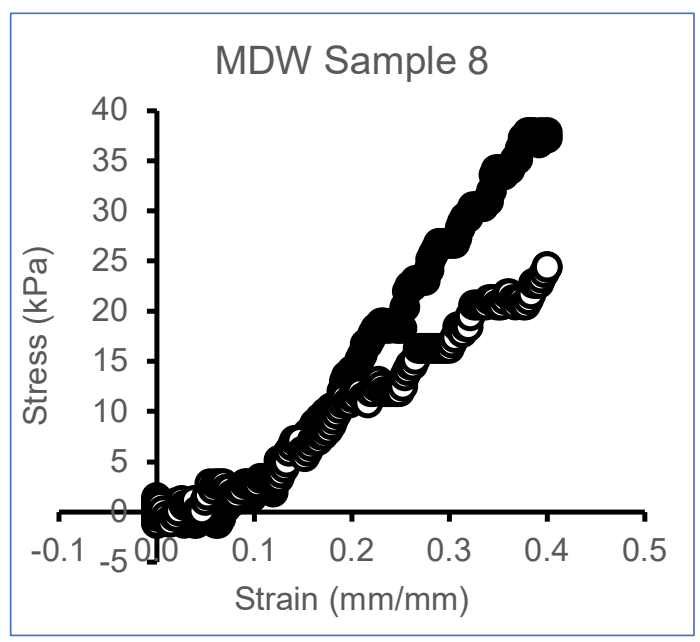

(H) 


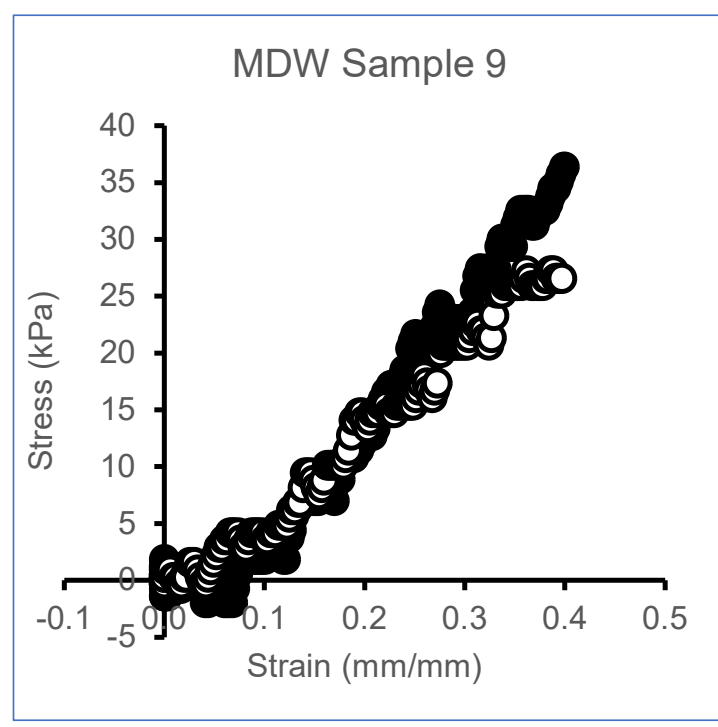

(I)

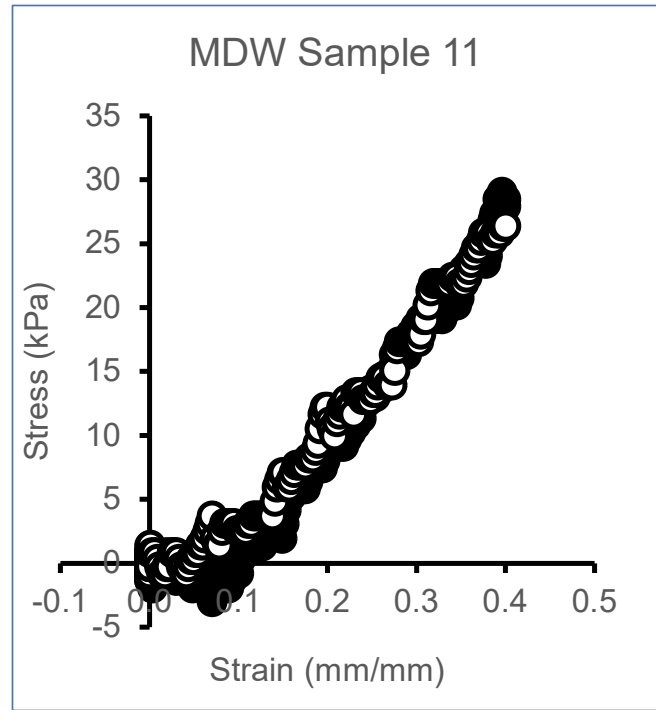

(K)

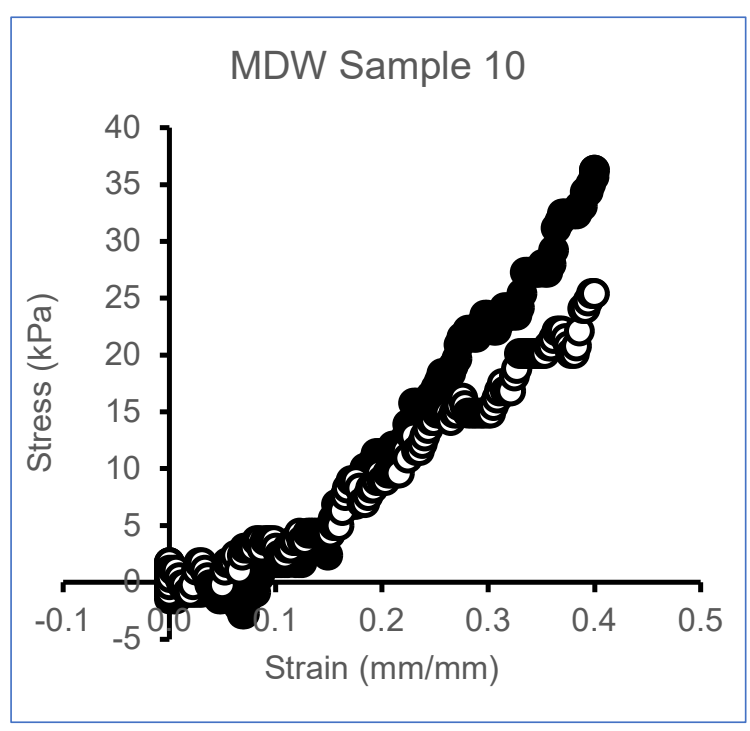

(J)

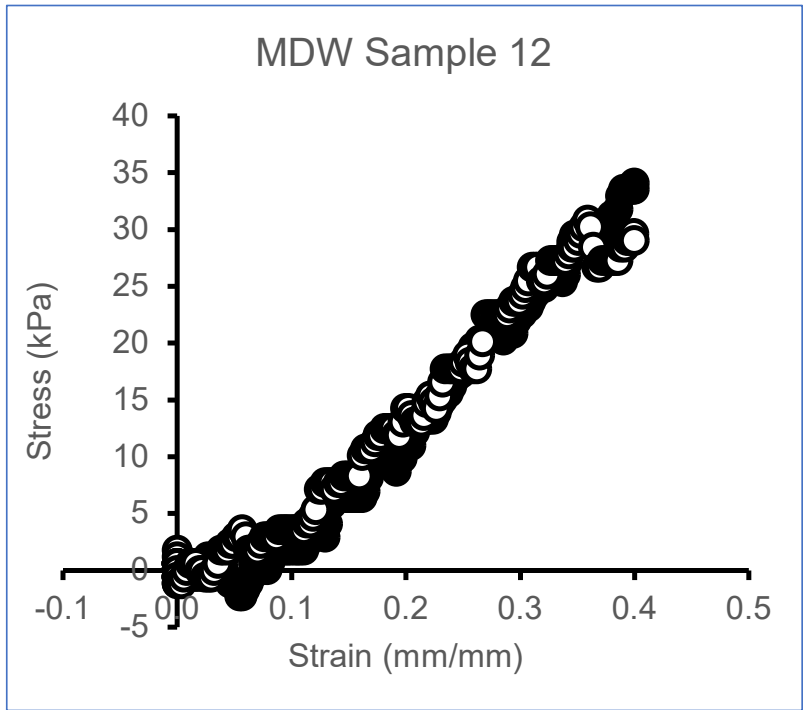

(L) 


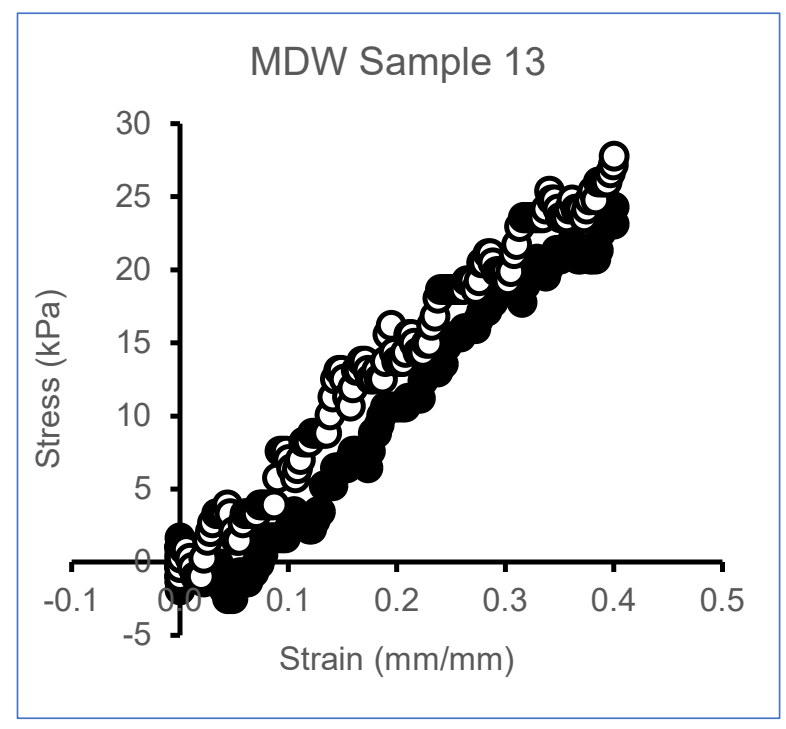

(M)

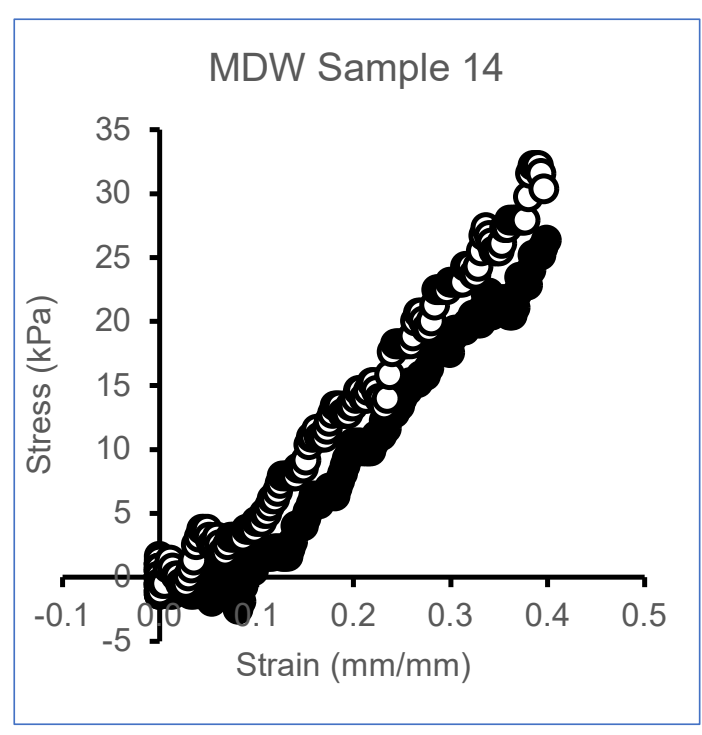

(N)

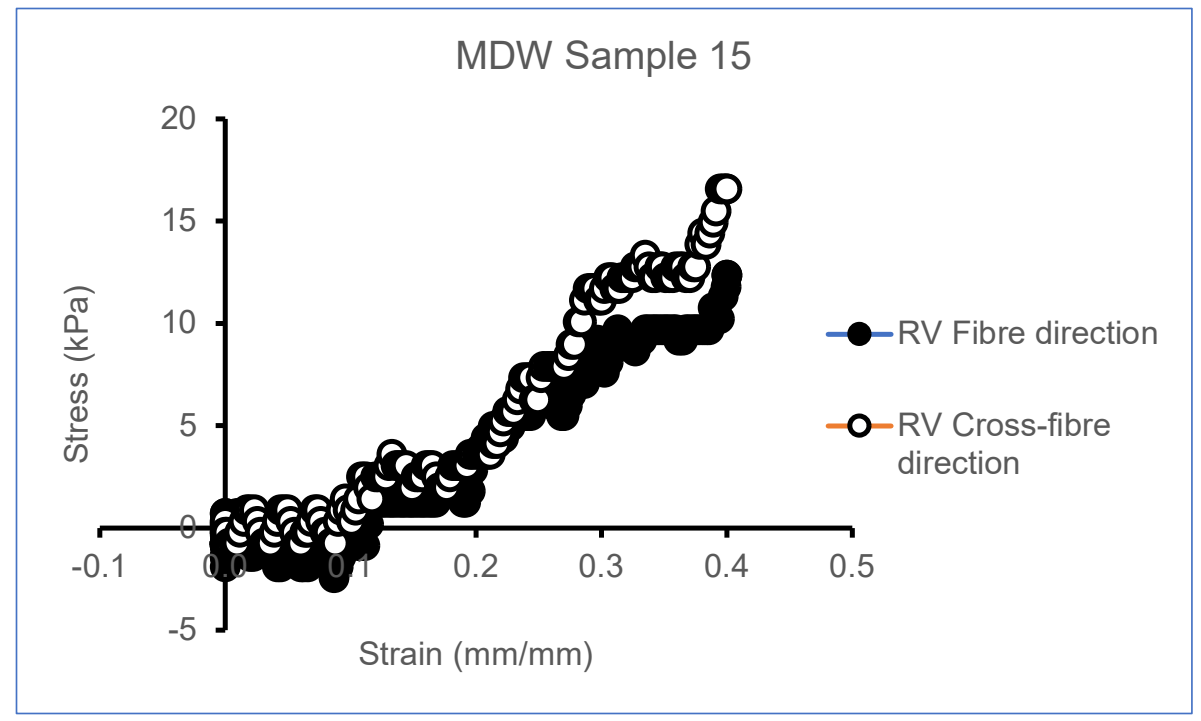

(O)

Figure 3. Stress vs Strain plots of MDW subjected to biaxial testing showing stresses in fibre and cross-fibre directions. 


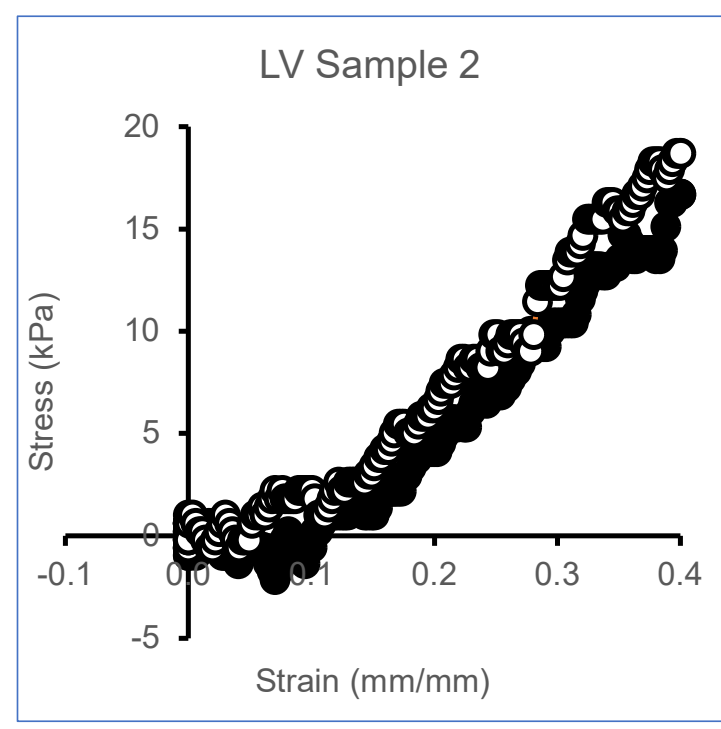

(A)

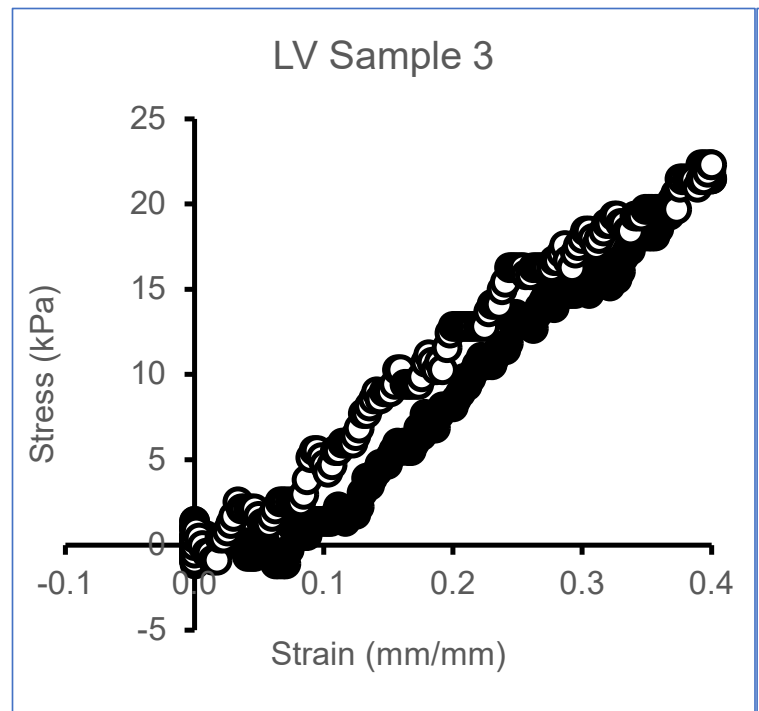

(C)

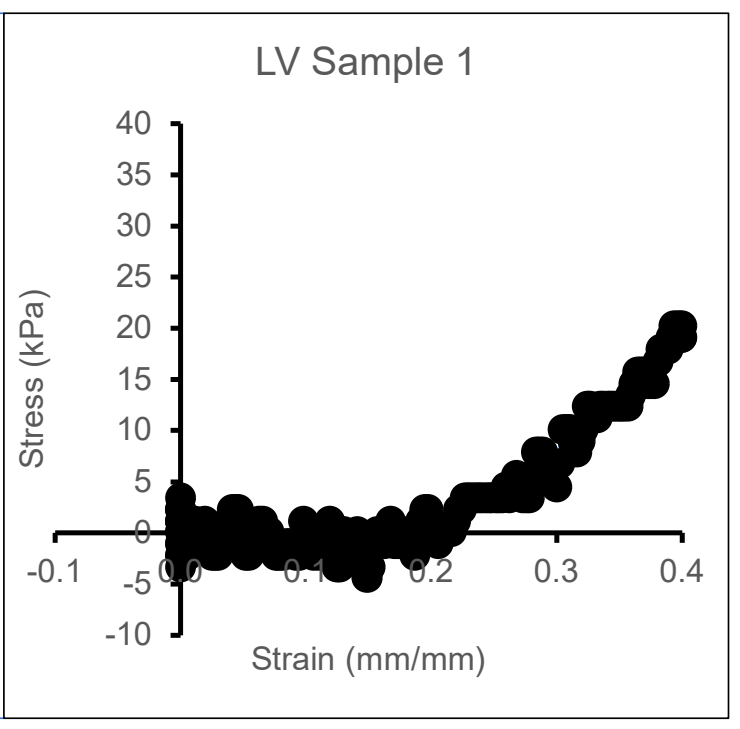

(B)

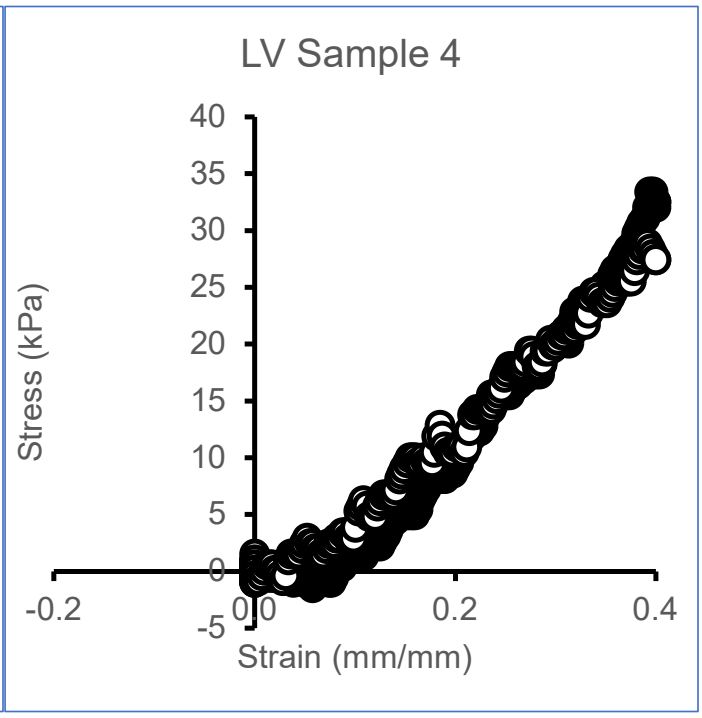

(D) 


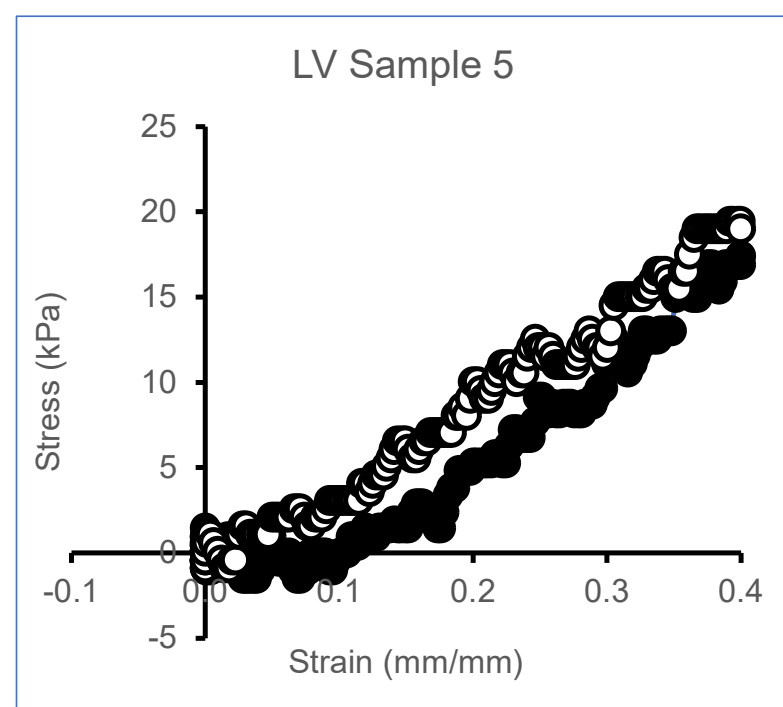

(E)

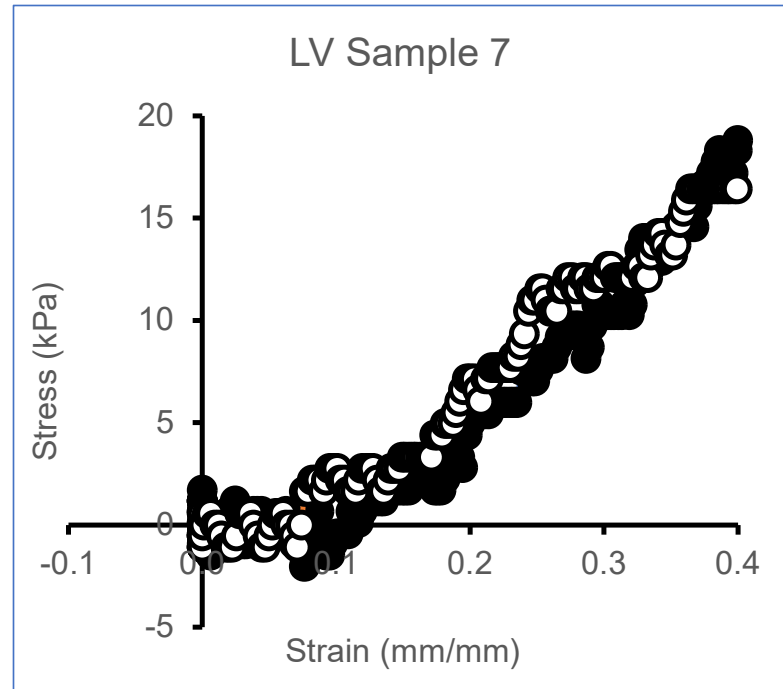

(G)

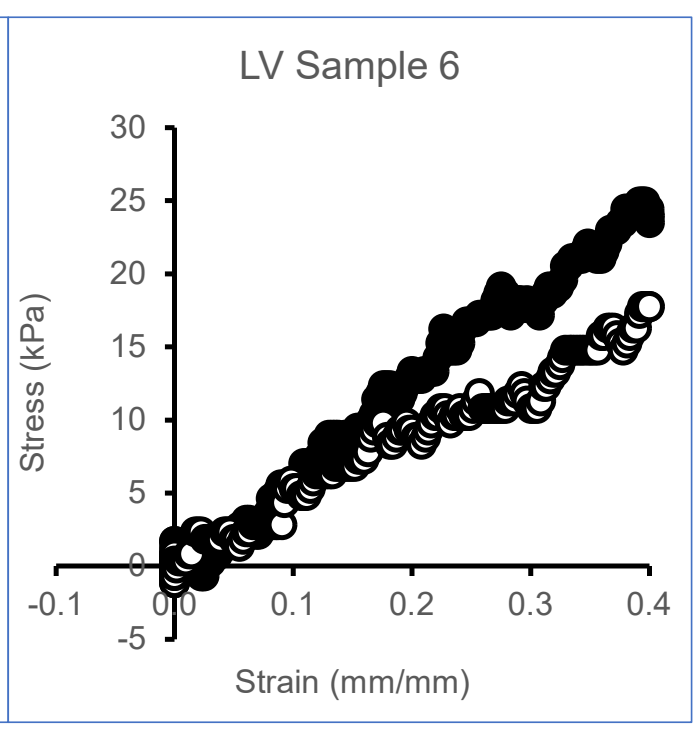

(F)

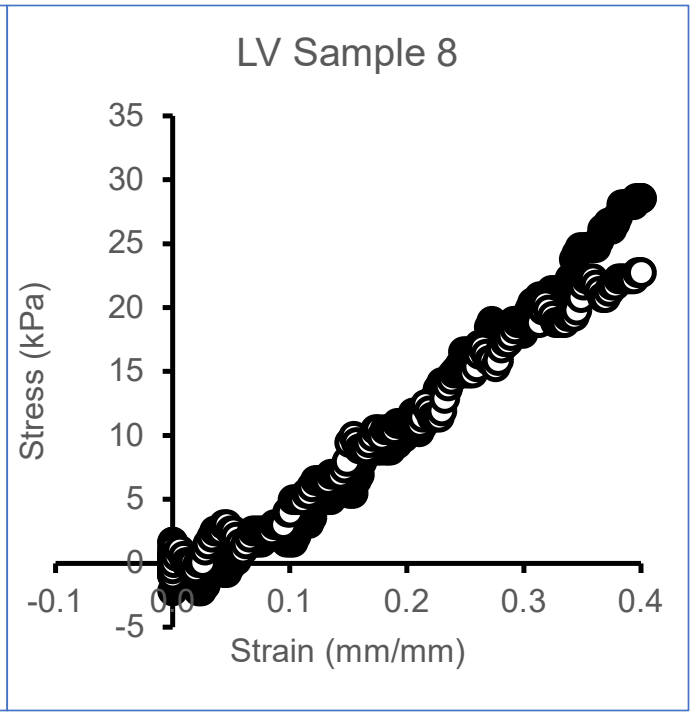

(H) 


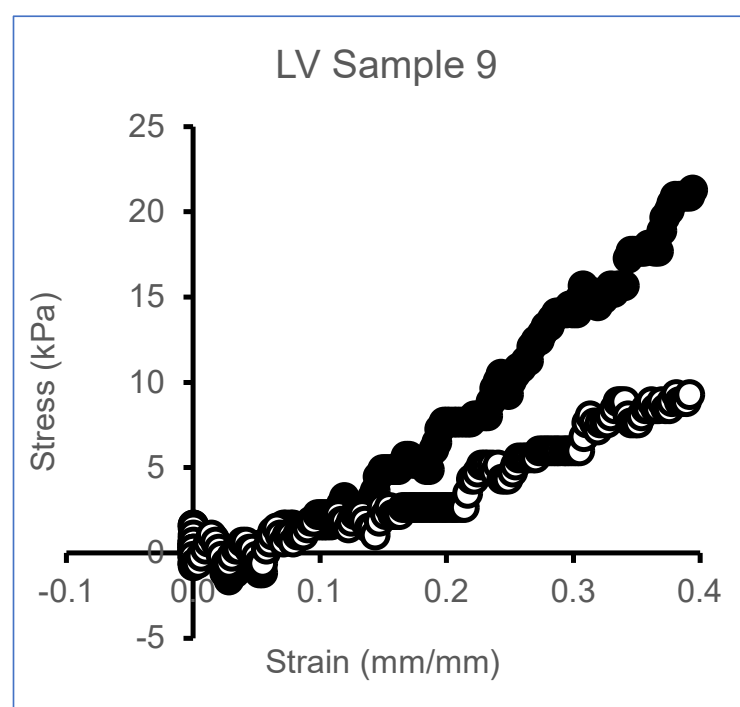

(I)

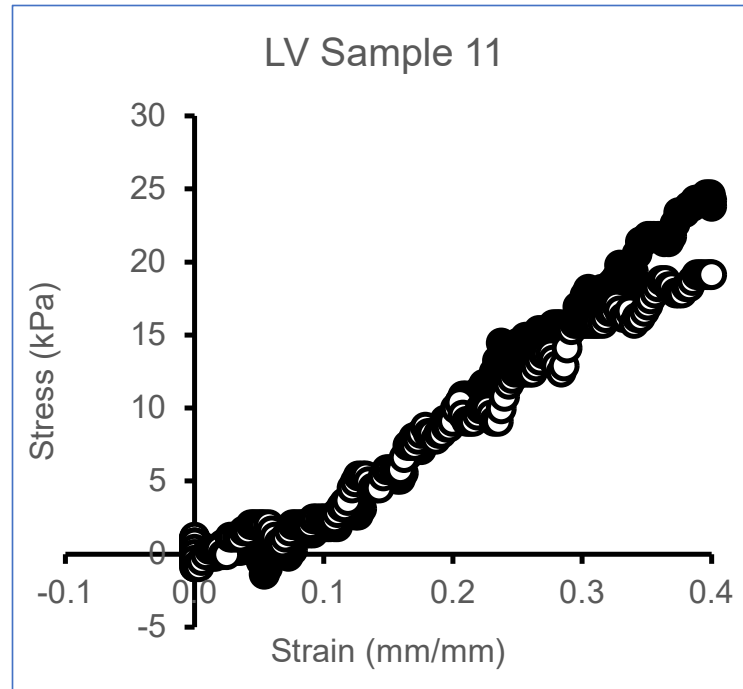

(J)

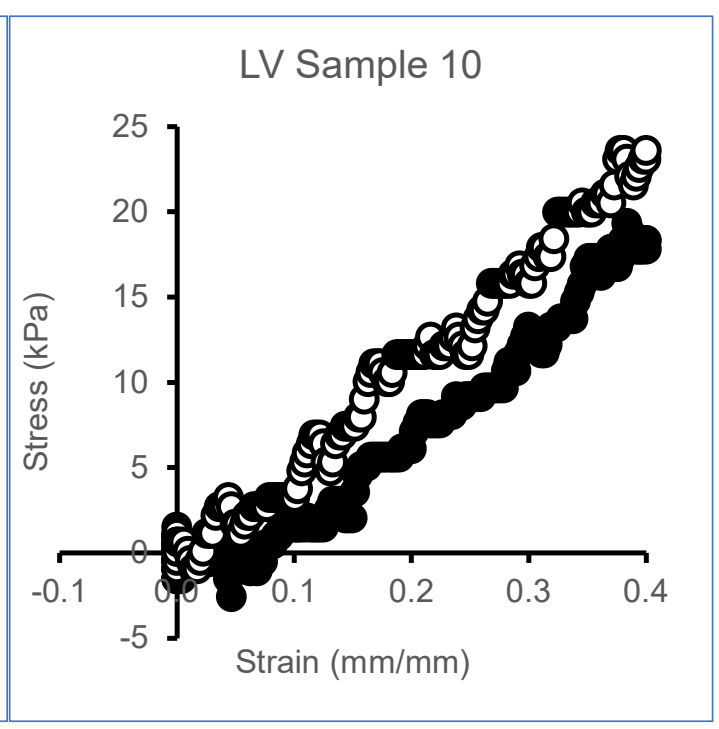

(J)

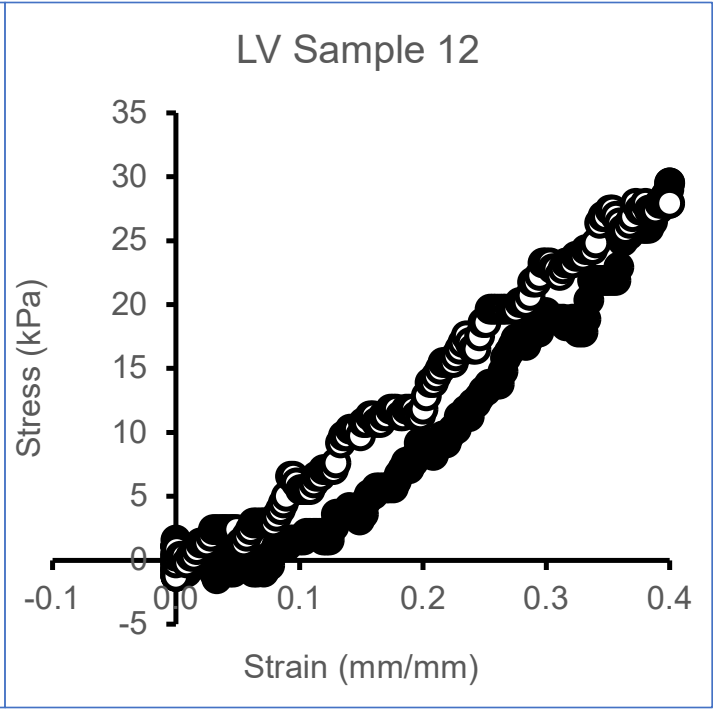

(K) 


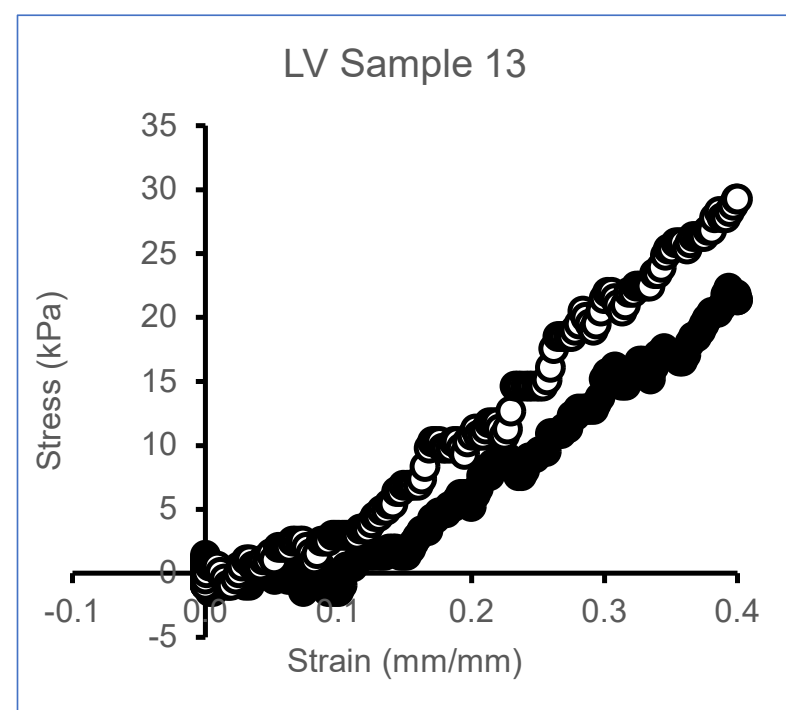

(L)

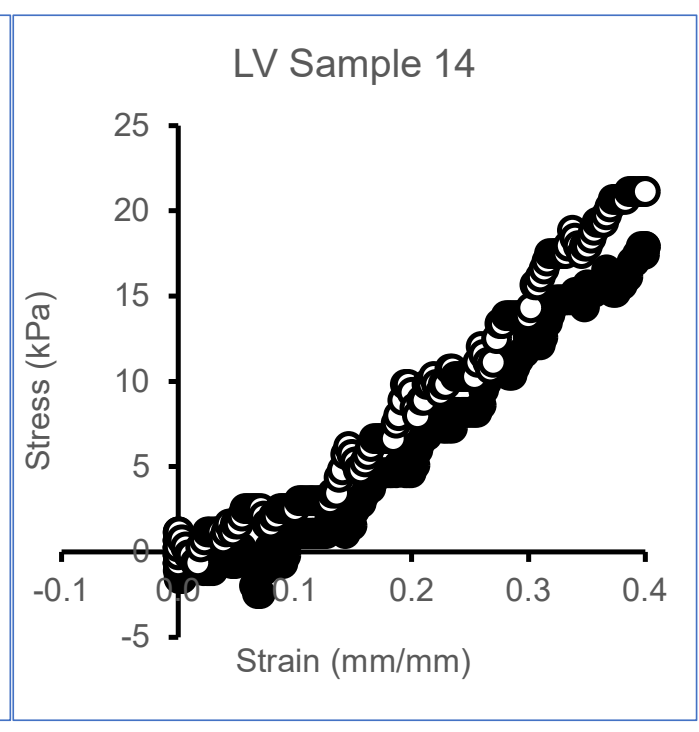

(M)

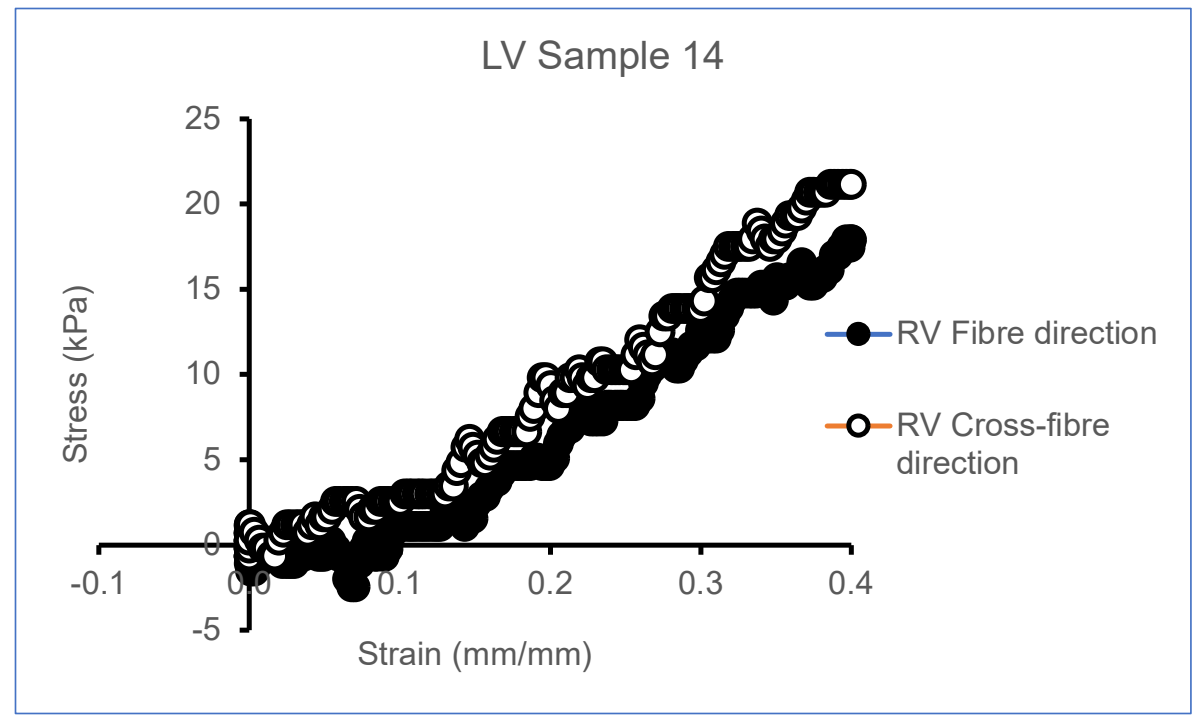

(N)

Figure 4. Stress vs Strain plots of LV subjected to biaxial testing showing stresses in fibre and cross-fibre directions.

Table1. LV maximum stress at $40 \%$ strain $(\mathrm{n}=14)$

\begin{tabular}{|c|c|c|}
\hline & $\begin{array}{l}\text { Cross-fibre } \\
\text { stress } \\
(\mathrm{kPa})\end{array}$ & $\begin{array}{l}\text { Fibre } \\
\text { stress } \\
(\mathrm{kPa})\end{array}$ \\
\hline LV Sample 1 & 20,23 & 35,06 \\
\hline LV Sample 2 & 16,69 & 18,71 \\
\hline LV Sample 3 & 21,46 & 22,28 \\
\hline LV Sample 4 & 32,03 & 27,41 \\
\hline LV Sample 5 & 16,92 & 19,00 \\
\hline
\end{tabular}




\begin{tabular}{lrr} 
LV Sample 6 & 23,48 & 17,76 \\
LV Sample 7 & 18,79 & 16,43 \\
LV Sample 8 & 28,54 & 22,72 \\
LV Sample 9 & 22,47 & 9,28 \\
LV Sample 10 & 17,80 & 23,61 \\
LV Sample 11 & 23,80 & 19,12 \\
LV Sample 12 & 29,50 & 27,94 \\
LV Sample 13 & 21,37 & 29,27 \\
LV Sample 14 & 17,91 & 21,14 \\
\hline Mean & 22,21 & 22,12 \\
\hline
\end{tabular}

Table 2. MDW maximum stress at $40 \%$ strain $(n=14)$

\begin{tabular}{lcc}
\hline & & Fibre \\
& $\begin{array}{c}\text { Cross-fibre } \\
\text { stress }\end{array}$ & $\begin{array}{c}\text { sPa }) \\
(\mathrm{kPa})\end{array}$ \\
\hline MDW Sample 1 & 39,00 & 31,98 \\
MDW Sample 2 & 34,90 & 18,25 \\
MDW Sample 3 & 36,00 & 23,24 \\
MDW Sample 4 & 35,77 & 13,49 \\
MDW Sample 5 & 46,84 & 27,56 \\
MDW Sample 6 & 37,36 & 27,16 \\
MDW Sample 7 & 38,64 & 32,77 \\
MDW Sample 8 & 37,83 & 24,44 \\
MDW Sample 9 & 37,04 & 27,24 \\
MDW Sample 10 & 36,25 & 25,39 \\
MDW Sample 11 & 27,90 & 26,36 \\
MDW Sample 12 & 33,53 & 29,02 \\
MDW Sample 13 & 23,13 & 27,79 \\
MDW Sample 14 & 26,36 & 30,36 \\
MDW Sample 15 & 12,34 & 16,58 \\
\hline Mean & 33,53 & 25,44 \\
\hline
\end{tabular}

Table 3. RV maximum stress at 40\% strain $(n=16)$

\begin{tabular}{lcc}
\hline & Cross- & \\
& fibre & Fibre \\
& Stress & Stress \\
& $(\mathrm{kPa})$ & $(\mathrm{kPa})$ \\
\hline RV Sample 1 & 7,35 & 22,16 \\
RV Sample 2 & 31,14 & 37,08 \\
RV Sample 3 & 18,30 & 30,33 \\
RV Sample 4 & 19,35 & 48,78
\end{tabular}




\begin{tabular}{lll} 
RV Sample 5 & 21,83 & 43,01 \\
RV Sample 6 & 20,23 & 35,06 \\
RV Sample 7 & 21,83 & 43,01 \\
RV Sample 8 & 20,23 & 35,06 \\
RV Sample 9 & 21,46 & 22,28 \\
RV Sample 10 & 28,52 & 34,10 \\
RV Sample 11 & 34,04 & 47,70 \\
RV Sample 12 & 15,84 & 26,44 \\
RV Sample 13 & 24,81 & 41,67 \\
RV Sample 14 & 20,52 & 37,41 \\
RV Sample 15 & 30,44 & 40,35 \\
RV Sample 16 & 27,46 & 15,77 \\
\hline Mean & 22,71 & 35,01 \\
\hline
\end{tabular}

\section{Methods}

3.1 Heart dissection and testing sample preparation

Wistar rats (200-250 gr) were euthanised by inhalation of 5\% halothane. Once breathing and heartbeat had stopped, the heart was dissected out. The atria, pulmonary trunk and all unwanted soft tissues were dissected away. For the LV sample, a full cross-section of $5 \times 5 \mathrm{~mm}$ was dissected out of the LV from the base to the apex of the rat heart. The samples were received from the University of Cape Town and carried to the University of South Africa in a temperature-controlled box. The mechanical tests were then conducted immediately after receipt of the samples. This study was approved by the Faculty of Health Sciences Animal Ethics Committee of the University of Cape Town on 6 May 2019 under reference number FHS AEC REF 019-019

\subsection{Biaxial tensile test}

CellScale Biaxial testing system was used to capture the mechanical properties of all tissue samples. All prepared tissue samples were mounted in the custom biaxial tensile material testing apparatus (BioTester 5000 CellScalle, Wateroo, ON, Canada®) specifically designed for soft tissue mechanical testing. The BioTester 5000 biaxial system is installed with a unique system that uses rakes for piercing the tissue. In this test, the four rakes (see Figure 1) are utilised to clamp the tissue sample for biaxial tensile testing. Average of 14 samples for LV, MDW and RV were harvested and subjected to equi-biaxial tensile testing. The major dimensions such as length, width and the thickness of each sample were measured using a Vernier calliper. To ensure the accuracy of the measurement, each dimension was measured four times and average dimensions were then utilised for further processing. Before collecting data, the precondition was conducted by applying a $10 \%$ strain on the sample at a strain rate of $0.001 / \mathrm{s}$. A preload of $5 \mathrm{mN}$ was applied for 0.53 seconds. To maintain hydration and mimicking the body temperature, saline $0.91 \% \mathrm{w} / \mathrm{v}$ of $\mathrm{NaCl}$ was placed in the bath and heated to $37{ }^{\circ} \mathrm{C}$ and maintained for the duration of testing. Each sample was subjected to $40 \%$ biaxial strain in the fibre and cross-fibre direction simultaneously at strain rate of $40 \%$ strain $/ 5$ seconds. $40 \%$ strain was selected to be the physiological magnitude of rat heart. 


\section{Discussion}

Mechanical properties of soft tissues have been utilized for decade in studying the mechanisms of diseases [1-5]. Accuracy of mechanical properties of soft tissues is vital in the developed of computational models. Biventricular subject specific heart models have been used for decades to study various stages of cardiovascular diseases including myocardial infarction [6,7]. The accurate computational models are critical in the development of therapies for different diseases $[2,8,9]$. Currently, when building the computational models, the mechanical properties of the heart are assumed to be the same in all regions of the heart [10-14]. This studies clearly shows that it is important to consider the different material properties of all regions in the heart. This is so because it is clear from the presented data that the is a different mechanical property in different heart regions, i.e. $\mathrm{RV}, \mathrm{MDW}$ and $\mathrm{LV}$.

Supplementary Materials: No supplementary data is available except data that is available here DOI: $10.17632 / \mathrm{y} 753 \mathrm{k} 82 \mathrm{jt} 4.2$.

Author Contributions: Conceptualization, T.F., F.N. and N.D.; methodology, F.N.; formal analysis, F.N.; investigation, F.N.; resources, F.N. and H.N.; data curation, F.N.; writing - original draft preparation, F.N.; writing-review and editing, H.M. T.F; and N.D.; visualization, F.N.; supervision, F.N.; project administration, H.M. and F.N.; funding acquisition, F.N. All authors have read and agreed to the published version of the manuscript.

Funding: Support from the National Research Foundation (NRF) Gran number (129380) is gratefully acknowledged. Unisa CAPEX Programme supported the acquisition of biaxial testing machine in the Department of Mechanical Engineering, School of Engineering, College of Science Engineering and Technology. We also acknowledge graduate researchers Mr Lebogang Lebea, Ms Lebogang Mathebela for their assistance with the biaxial mechanical testing.

Data Availability Statement: The dataset presented in this paper can be found publicly deposited here DOI: $10.17632 / \mathrm{y} 753 \mathrm{k} 82 \mathrm{jt} 4.2$.

Acknowledgments: Support from the National Research Foundation (NRF) Gran number (129380) is gratefully acknowledged. Unisa CAPEX Programme supported the acquisition of biaxial testing machine in the Department of Mechanical Engineering, School of Engineering, College of Science Engineering and Technology. We also acknowledge graduate researchers Mr Lebogang Lebea, Ms Lebogang Mathebela for their assistance with the biaxial mechanical testing.

Conflicts of Interest: The authors declare no conflict of interest. The funders had no role in the design of the study; in the collection, analyses, or interpretation of data; in the writing of the manuscript, or in the decision to publish the results.

\section{References}

1. Nemavhola, F., Biaxial quantification of passive porcine myocardium elastic properties by region. Engineering Solid Mechanics, 2017. 5(3): p. 155-166.

2. Nemavhola, F., Detailed structural assessment of healthy interventricular septum in the presence of remodeling infarct in the free wall-A finite element model. Heliyon, 2019. 5(6): p. e01841.

3. Ngwangwa, H.M. and F. Nemavhola, Evaluating computational performances of hyperelastic models on supraspinatus tendon uniaxial tensile test data. Journal of Computational Applied Mechanics, 2021. 52(1): p. 27-43.

4. Ndlovu, Z., F. Nemavhola, and D. Desai, BIAXIAL MECHANICAL CHARACTERIZATION AND CONSTITUTIVE MODELLING OF SHEEP SCLERA SOFT TISSUE. Russian Journal of Biomechanics/Rossijski Zurnal Biomehaniki, 2020. 24(1).

5. Sirry, M.S., et al., Characterisation of the mechanical properties of infarcted myocardium in the rat under biaxial tension and uniaxial compression. journal of the mechanical behavior of biomedical materials, 2016. 63: p. 252-264.

6. Xi, C., G.S. Kassab, and L.C. Lee, Microstructure-based finite element model of left ventricle passive inflation. Acta biomaterialia, 2019. 90: p. 241-253.

7. Sack, K.L., et al., Intra-myocardial alginate hydrogel injection acts as a left ventricular mid-wall constraint in swine. Acta Biomaterialia, 2020. 111: p. 170-180. 
8. Nemavhola, F., Fibrotic infarction on the LV free wall may alter the mechanics of healthy septal wall during passive filling. Biomedical materials and engineering, 2017. 28(6): p. 579-599.

9. Masithulela, F.J., Computational biomechanics in the remodelling rat heart post myocardial infarction. 2016.

10. Masithulela, F., Bi-ventricular finite element model of right ventricle overload in the healthy rat heart. Bio-medical materials and engineering, 2016. 27(5): p. 507-525.

11. Masithulela, F. The effect of over-loaded right ventricle during passive filling in rat heart: A biventricular finite element model. in ASME International Mechanical Engineering Congress and Exposition. 2015. American Society of Mechanical Engineers.

12. Masithulela, F. Analysis of passive filling with fibrotic myocardial infarction. in ASME international mechanical engineering congress and exposition. 2015. American Society of Mechanical Engineers.

13. Nemavhola, F., Mechanics of the septal wall may be affected by the presence of fibrotic infarct in the free wall at end-systole. International Journal of Medical Engineering and Informatics, 2019. 11(3): p. 205-225.

14. Wenk, J.F., et al., Biventricular finite element modeling of the Acorn CorCap Cardiac Support Device on a failing heart. The Annals of thoracic surgery, 2013. 95(6): p. 2022-2027. 